\title{
Seeing more clearly despite the ptosis
}

\author{
Sudish C. Murthy, MD, PhD
}

\footnotetext{
From the Department of Thoracic and Cardiovascular Surgery, Heart and Vascular Institute, Cleveland Clinic, Cleveland, Ohio.

Funded in part by the Daniel and Karen Lee Endowed Chair in Thoracic Surgery, which is held by Dr Murthy. Disclosures: Author has nothing to disclose with regard to commercial support.

Received for publication Dec 19, 2017; accepted for publication Dec 20, 2017; available ahead of print April 12, 2018.

Address for reprints: Sudish C. Murthy, MD, PhD, Department of Thoracic and Cardiovascular Surgery, Heart and Vascular Institute, Cleveland Clinic, 9500 Euclid Ave, Desk J4-1, Cleveland, OH 44195 (E-mail: murthys1@ ccf.org).

J Thorac Cardiovasc Surg 2018;155:2736-7

$0022-5223 / \$ 36.00$

Copyright (c) 2018 by The American Association for Thoracic Surgery

https://doi.org/10.1016/j.jtcvs.2017.12.085
}

Myasthenia gravis is a surprisingly mysterious disease. Symptoms are very well cataloged and include ptosis, diplopia, and difficulty in chewing and swallowing, but in more advanced disease states weakness of the upper and lower limbs and even pulmonary failure due to weakness of respiratory muscles are also seen. Moreover, pathogenesis also seems unambiguous and straightforward because presence of acetylcholine receptor antibodies is essentially pathognomonic. Finally, diagnosis is definitively established when there is a favorable response to acetylcholinesterase inhibition. Seems simple enough, right? But this is merely where all the low-hanging fruit has been harvested and the real knowledge gap begins.

It is unclear how or why the disease starts and very confusing as to how it might end, and given the tangible quality and quantity-of-life issues in play, our lack of insight becomes magnified. The course of the disease waxes and wanes, and we currently remain impotent in our prognostic capacities in this regard as well. Cholinergic drugs are the mainstay for many patients, but treatments can escalate quickly to much more morbid immunosuppression. A small proportion advance to plasma exchange and intravenous immunoglobulin administration. At the back end of options quietly sits thymectomy, just waiting to be called into the fray.

There is little doubt that thymectomy works, and randomized data confirm inclusion of thymectomy as an important part of the treatment armamentarium. ${ }^{1}$ However, it does not work all the time, and when it does work, improvement is highly variable, ranging from mild reduction of immunosuppressive medications to complete remission. There is almost certainly morbidity associated with thymectomy and a cost to the patient from this standpoint. Consequently, neurology teams have always been somewhat reluctant to refer patients for thymectomy given the variability of efficacy, despite clear evidence supporting utility. I suspect that for most treating teams, thymectomy remains a 12thhour reprieve option that is probably not in the patient's best interest.

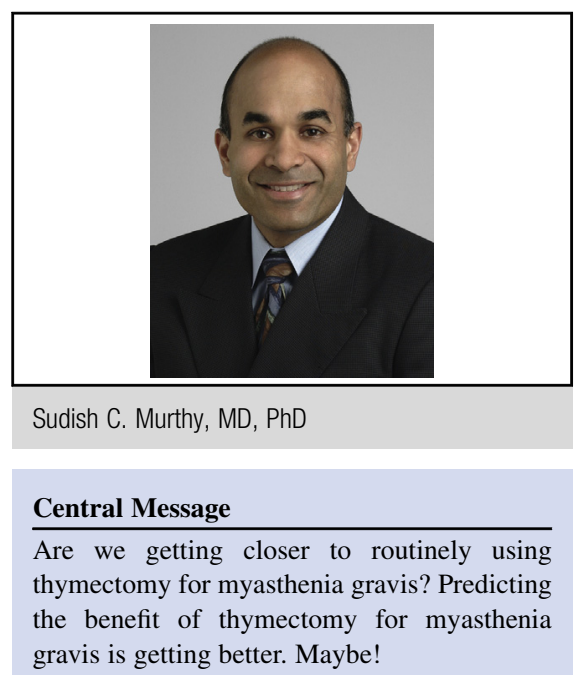

See Article page 2738 .

How can we move forward with clear, randomized evidence of importance while still being unclear as to the strength of that importance? Takahagi and colleagues ${ }^{2}$ suggest that 3-dimensional computed tomography (3D CT) volumetry might provide a new predictive strategy to identify those patients more likely to benefit from thymectomy a priori. Based on a density cut-off, the authors examined surrogates for response to thymectomy that appear to be positively correlated.

There is much left to be desired from the study because it is very small, complicated by inclusion of patients with thymoma, and poorly controlled for preoperative myasthenia gravis treatment and surgical approach of thymectomy. Even more concerning is that the surrogate for response was reduction of serum anticholine receptor antibody concentration. The leap in logic is made that with the 3D CT volumetry cut-off of 30 Hounsfield units, patients are segregated into responders to thymectomy by antibody concentration, not by symptom scores, not by prednisone or azathioprine reduction, and not by long-term control of the disease. That is some stretch.

This study is hardly a ringing endorsement for the value of 3D CT volumetry as a prognostic tool for responders to thymectomy for myasthenia gravis, but is very provocative. The findings will definitely need to be amplified on a much grander scale. Perhaps this group can get together with the Thymectomy Trial in Non-Thymomatous Myasthenia Gravis Patients Receiving Prednisone Therapy (MGTX) study group and meld their efforts together. That just might enlighten us all. 


\section{References}

1. Wolfe GI, Kaminski HJ, Aban IB, Minisman G, Kuo HC, Marx A, et al. Randomized trial of thymectomy in myasthenia gravis. $N$ Engl J Med. 2016;375: 511-22.
2. Takahagi A, Omasa M, Chen-Yoshikawa TF, Hamaji M, Yoshizawa A, Sozu T, et al. Anterior mediastinal tissue volume is correlated with antiacetylcholine receptor antibody level in myasthenia gravis. J Thorac Cardiovasc Surg. 2018; $155: 2738-44$ 